\title{
Oreoglanis infulatus, a new species of glyptosternine catfish (Siluriformes: Sisoridae) from central Vietnam
}

\author{
H. H. NG*† AND J. FreYhOF† \\ *Fish Division, Museum of Zoology, University of Michigan, 1109 Geddes Avenue, \\ Ann Arbor, Michigan 48109-1079, U.S.A. and †Leibniz-Institut für Gewässerökologie \\ und Binnenfischerei, Müggelseedamm 310, 12561 Berlin, Germany
}

(Received 2 December 2000, Accepted 25 July 2001)

\begin{abstract}
A new species of glyptosternine catfish, Oreoglanis infulatus, is described from the Lam River drainage in central Vietnam. The new species is distinguished from all its congeners by possessing the following combination of characters: a dark band running across the anal fin, a lunate and uniformly dark caudal fin, the lower lip lacking a medial notch and with a lobulate posterior margin, maxillary barbel with a rounded tip, length of caudal peduncle 19.0-22.6 $\% L_{\mathrm{S}}$, depth of caudal peduncle $2 \cdot 6-3 \cdot 2 \% L_{\mathrm{S}}$, post-adipose distance $6 \cdot 8-8 \cdot 0 \% L_{\mathrm{S}}$, eye diameter $10 \cdot 5-12 \cdot 1 \% L_{\mathrm{H}}, 12$ principal caudal-fin rays.

(C) 2001 The Fisheries Society of the British Isles
\end{abstract}

Key words: Oreoglanis; central Vietnam; new species.

\section{INTRODUCTION}

Catfishes of the sub-family Glyptosterninae are rheophilic fishes with strongly depressed heads and bodies, flattened maxillary barbels and greatly enlarged pectoral and pelvic fins modified to form an adhesive apparatus. One such genus, Oreoglanis Smith, 1933, is characterized by a continuous postlabial groove of the lower jaw and unusual (heterodont) dentition: pointed teeth in the upper jaw and inner rows of the dentary (lower jaw) tooth patches and truncate-spatulate teeth in the outer rows of the dentary tooth patches.

The systematic relationships within glyptosternines are poorly understood despite numerous studies (Hora \& Silas, 1952; Chu, 1979). Oreoglanis may not represent a natural group, its paraphyly with Pareuchiloglanis and Pseudexostoma (and possibly including Myersglanis and Parachiloglanis) having been demonstrated $(\mathrm{He}, 1995,1996)$. Be that as it may, a systematic reappraisal of the validity of the various glyptosternine genera is difficult, given the paucity of material and the difficulty in gaining access to many types, which are deposited in Indian and Chinese museums. Following the rationale of $\mathrm{Ng} \&$ Kottelat (1999), Oreoglanis is considered tentatively to be a valid genus as originally defined (see above) for easier comparisons. During an ichthyological survey of the river drainages in central Vietnam undertaken by the second author, specimens of Oreoglanis were obtained, which on comparison with other known species were found to represent an undescribed species. This species is described here as $O$. infulatus, a new species.

\$Author to whom correspondence should be addressed. Tel.: +1 734647 2192; fax: +1 734763 4080; email: heokheen@umich.edu 


\section{MATERIALS AND METHODS}

All fish were caught using a DEKA 3000 portable electroshocker and fixed in 5\% formaldehyde and transferred to $70 \%$ ethanol for long-term storage. Measurements were made point-to-point with dial callipers and recorded to $0.1 \mathrm{~mm}$. $\mathrm{Ng} \&$ Rainboth (2001) is followed for all measurements and counts. Drawings of the specimens were made with a Wild M5 fitted with a camera lucida. Eschmeyer (1998) is followed for all institutional codes.

\section{RESULTS}

OREOGLANIS INFULATUS SP. NOV. [FIGS 1 AND 2]

Holotype

ZFMK 35719, 76.1 mm $L_{S}$; Vietnam: Ha Tinh province, stream at Son Kim, a tributary of Song Lam $\left(18^{\circ} 24^{\prime} 25^{\prime \prime} \mathrm{N}\right.$; $105^{\circ} 11^{\prime} 10^{\prime \prime}$ E); J. Freyhof, F. Herder \& D. V. Serov, 11 April 1999.

\section{Paratypes}

UMMZ 238025, 6 ex., 42·2-72.6 mm $L_{\mathrm{S}}$; ZFMK 35720-35725, 6 ex., 40·3$72 \cdot 4 \mathrm{~mm} L_{\mathrm{S}}$; data as for holotype.

\section{Diagnosis}

Oreoglanis infulatus is distinguished from all its congeners by possessing the following combination of characters: a dark band running across the anal fin, a lunate and uniformly dark caudal fin, the lower lip lacking a medial notch and with a fimbriated posterior margin, maxillary barbel with a rounded tip, length of caudal peduncle $19 \cdot 0-22 \cdot 6 \% L_{\mathrm{S}}$, depth of caudal peduncle $2 \cdot 6-3 \cdot 2 \% L_{\mathrm{S}}$, post-adipose distance $6 \cdot 8-8 \cdot 0 \% L_{\mathrm{S}}$, eye diameter $10 \cdot 5-12 \cdot 1 \% L_{\mathrm{H}}, 12$ principal caudal-fin rays.

\section{Description}

Head and body moderately broad and very strongly depressed. Mouth and gape inferior with broad, thin and papillate lips. Lower lip lacking median notch, posterior margin with fimbriate projections. Postlabial groove on lower jaw present and uninterrupted. Teeth on upper jaw pointed and in large broad band with small median indentation and rounded ends on both sides. Teeth on lower jaw present in two well separated patches of roughly triangular shape (with a medial toothless gap) and of two kinds: outer teeth truncate-spatulate, with a curved inner face; inner teeth pointed as in those of upper jaw. Eyes small, dorsolaterally situated and subcutaneous. Gill openings extending to middle of pectoral-fin base. Maxillary barbels flattened, with surrounding flap of skin and rounded tip; ventral surface with numerous plicae, posterior edge with lobulate projections (Fig. 2).

Dorsal fin without spine and i,5,i (6) rays. Adipose fin with long base. Anal fin with ii,3,i (6) rays. Caudal fin lunate, with $5 / 6$ (1) or 6/6 (5) rays; lower principal rays extended into a long, thin strap in mature males. Pelvic fin greatly enlarged, with convex distal margin and i,5 (4) rays; first ray greatly flattened and with numerous plicae on ventral surface. Pectoral fin greatly enlarged, without spine and with i,17 (3), or i,18 (3) rays; first ray greatly flattened and with numerous plicae on ventral surface. 
(a)

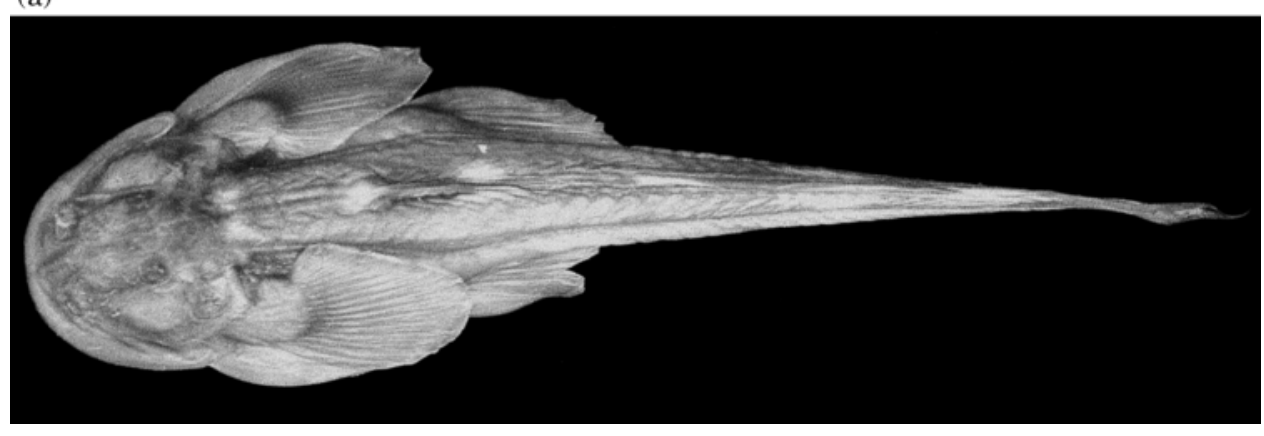

(b)

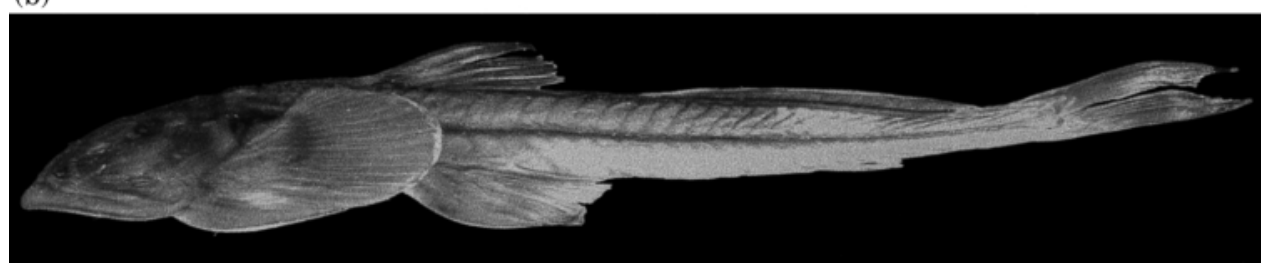

(c)

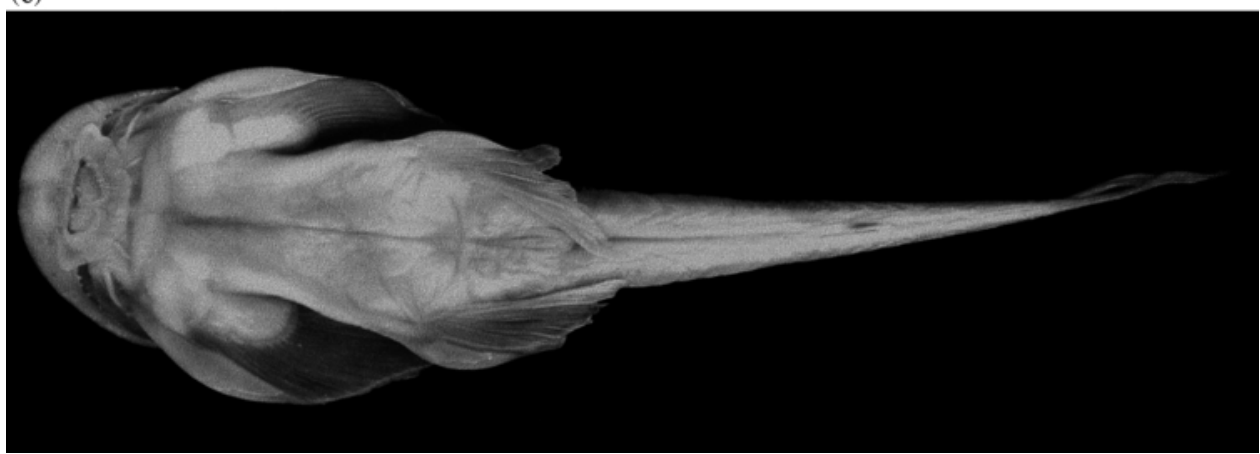

FIG. 1. Oreoglanis infulatus, UMMZ 238025, paratype, $70.9 \mathrm{~mm} L_{\mathrm{S}}$; Vietnam: Song Lam basin. (a) Dorsal view; (b) lateral view; (c) ventral view.

In $\% L_{\mathrm{S}}$ : body depth at anus $6 \cdot 3-8 \cdot 4$, predorsal length $32 \cdot 4-36 \cdot 5$, preanal length $73 \cdot 0-75 \cdot 9$, prepelvic length $35 \cdot 8-39 \cdot 4$, prepectoral length $14 \cdot 8-19 \cdot 7$, length of dorsal-fin base $9 \cdot 4-10 \cdot 2$, length of adipose-fin base $31 \cdot 7-36 \cdot 0$, dorsal to adipose distance $13 \cdot 2-15 \cdot 7$, post-adipose distance $6 \cdot 8-8 \cdot 0$, length of anal-fin base $2 \cdot 6-5 \cdot 1$, length of pelvic fin 20.4-21.7, length of pectoral fin $25 \cdot 3-26 \cdot 4$, depth of caudal peduncle $2 \cdot 6-3 \cdot 2$, length of caudal peduncle $19 \cdot 0-22 \cdot 6$, length of caudal fin 17.9-18.3 (males), 15.2-17.8 (females), head length 21.4-24.7, head width 19.3-21.3, head depth 7.7-7.9; in $\% L_{\mathrm{H}}$ : snout length $58 \cdot 8-61 \cdot 3$, interorbital distance $24 \cdot 0-29 \cdot 1$, eye diameter $10 \cdot 5-12 \cdot 1$, length of nasal barbel $17 \cdot 6-32 \cdot 0$, length of maxillary barbel $63 \cdot 0-68 \cdot 4$, length of inner mandibular barbel $5 \cdot 3-11 \cdot 2$, length of outer mandibular barbel $13 \cdot 7-20 \cdot 0$. Vertebrae $24+16=40$ (4) or $25+16=41(2)$. 


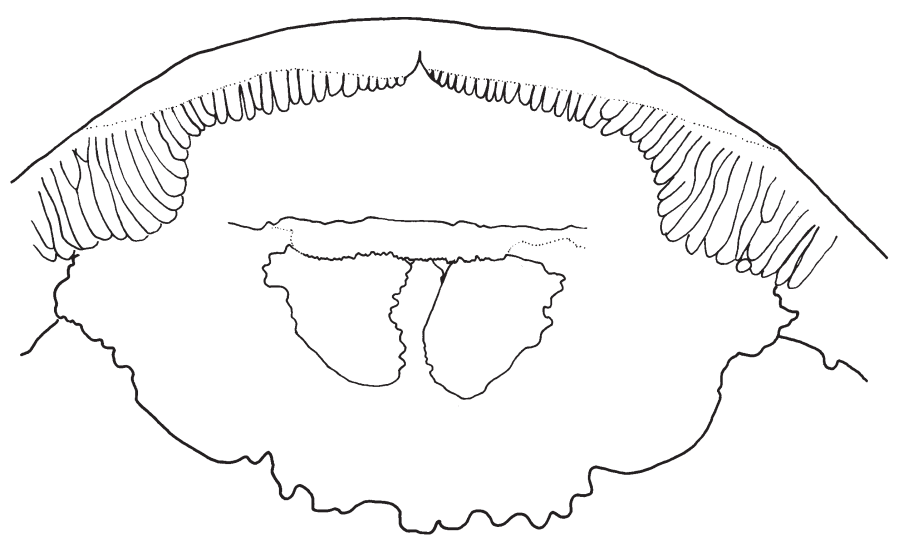

FIG. 2. Schematic illustration of the lower lip margin of $O$. infulatus, paratype, $70.9 \mathrm{~mm} L_{\mathrm{S}}$. Scale bar $=5 \mathrm{~mm}$.

(a)

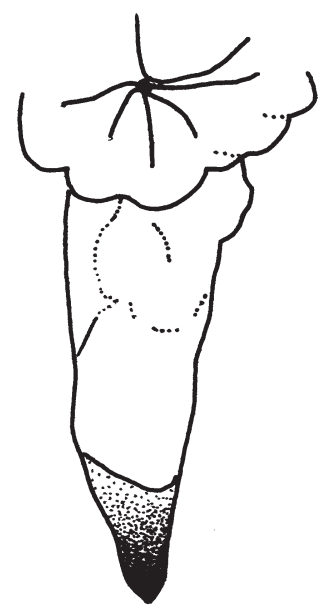

(b)

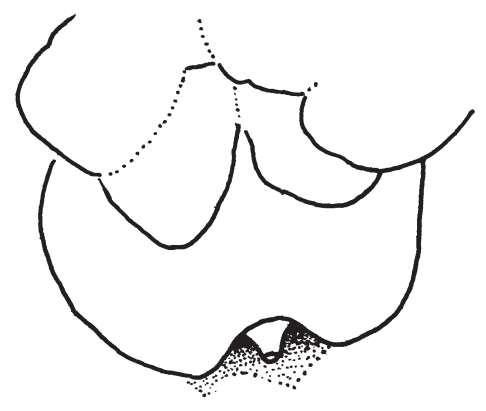

FIG. 3. Schematic illustration of the ventral view of the anus and external genitalia of $O$. infulatus: (a) male, UMMZ 238025, paratype, $70.9 \mathrm{~mm} L_{\mathrm{S}}$; (b) female, UMMZ 238025, paratype, $68.2 \mathrm{~mm} L_{\mathrm{S}}$. Scale bar $=1 \mathrm{~mm}$.

Males with a small genital papilla located immediately posterior to anus in a V-shaped depression [Fig. 3(a)]. Females with a small genital papilla located in a small depression posterior to a rounded protuberance located immediately posterior to anus [Fig. 3(b)].

\section{Colouration}

In $70 \%$ ethanol: brown on dorsal and lateral surfaces of head and body, light yellow on ventral region. Dorsal surfaces of head and body with a series of small faint light yellow patches: two ovoid patches on occipital region, an ovoid patch on base of first dorsal-fin ray, an elliptical patch on anterior base of adipose-fin 
and another on posterior base of adipose-fin. Faint pale yellow stripes occasionally present on dorsolateral surface, running along entire length of body above lateral line. Dorsal and caudal fins brown; dorsal surfaces of pectoral and pelvic fins brown, with ventral surfaces of pectoral and pelvic fins light yellow. Anal fin light yellow, with a brown transverse band running across middle third. Dorsal surface of barbels brown, ventral surface light yellow.

\section{Distribution}

Presently known only from one headwater of the Lam River drainage in central Vietnam.

\section{Etymology}

From the Latin infula, meaning band, in reference to the dark band on the anal fin. Used as an adjective.

\section{Notes on biology}

The species was collected in a steeply sloping rainforest stream 1-3 m wide. Oreoglanis infulatus was obtained only in waterfalls where the fish were found adhering to vertical surfaces of rocks. The fish were found along with Schistura antennata Freyhof \& Serov, 2001 and Schistura hingi (Herre, 1934).

\section{Remarks}

To date, eight species of Oreoglanis are recognized as valid ( $\mathrm{Ng} \&$ Rainboth, 2001), viz. O. macropterus (Vinciguerra, 1890), O. siamensis Smith, 1933, O. delacouri (Pellegrin, 1936), O. hypsiurus $\mathrm{Ng} \&$ Kottelat, 1999, O. frenatus $\mathrm{Ng} \&$ Rainboth, 2001, O. insignis Ng \& Rainboth, 2001, O. lepturus Ng \& Rainboth, 2001, and $O$. setiger $\mathrm{Ng} \&$ Rainboth, 2001. This now raises the number of known species in the genus to nine. Oreoglanis infulatus differs from all congeners in having a dark band running across the anal fin ( $v$. absence of dark colouration on anal fin). It belongs to the $O$. delacouri species group $(\mathrm{Ng} \&$ Rainboth, 2001) and thus differs from O. insignis, O. macropterus, O. setiger and $O$. siamensis in having a lunate ( $v$. truncate) caudal fin and a lower lip lacking a medial notch ( $v$. notched medially) and with a lobulate ( $v$. entire) posterior margin (Fig. 2). Oreoglanis infulatus also has a more slender caudal peduncle $\left(2 \cdot 6-3 \cdot 2 \% L_{\mathrm{S}} v \cdot 3 \cdot 8-8 \cdot 7\right)$ than $O$. macropterus, $O$. setiger and $O$. siamensis, and maxillary barbels with a rounded tip ( $v$. pointed tip in $O$. siamensis).

Oreoglanis infulatus differs from $O$. delacouri, O. lepturus and $O$. hypsiurus in having fewer principal caudal-fin rays (12v. 14), a smaller post-adipose distance $\left(6 \cdot 8-8 \cdot 0 \% L_{\mathrm{S}} v \cdot 8 \cdot 5-15 \cdot 4\right)$ and a uniformly dark caudal fin (v. light-coloured upper principal caudal-fin rays), and from O. frenatus in having the adipose fin separate from ( $v$. confluent with) the upper principal caudal rays, a shorter caudal peduncle $\left(19 \cdot 0-22 \cdot 6 \% L_{\mathrm{S}}\right.$ v. 23.6-27.1) and larger eye $\left(10 \cdot 5-12 \cdot 1 L_{\mathrm{H}} v\right.$. 7.5-9.8). It further differs from $O$. hypsiurus and $O$. lepturus in having a larger eye (eye diameter $10 \cdot 5-12 \cdot 1 \% L_{\mathrm{H}}$ v. 8·2-10.6).

We thank N. T. Nga, Vietnamese-Russian Science and Technological Tropical Center, Ho Chi Minh City, D. V. Serov, Russian Academy of Science, Institute of Ecology and Evolution, Moscow and F. Herder, Zoological Research Institute and Museum Alexander Koenig, Bonn for the logistic support in Vietnam. Funding for this project 
has been supported by the Rackham School of Graduate Studies of the University of Michigan and by 'Volkswagenstiftung' to the second author.

\section{References}

Chu, X.-L. (1979). Systematics and evolutionary pedigree of the glyptosternoid fishes (family Sisoridae). Acta Zootaxonomica Sinica 4, 72-82.

Eschmeyer, W. N. (Ed.) (1998). Catalog of Fishes. San Francisco: California Academy of Sciences.

He, S.-P. (1995). The analysis of historical biogeography for the glyptosternoid fishes (Teleostei: Siluriform, Sisoridae). Biogeographica 71, 145-160.

He, S.-P. (1996). The phylogeny of the glyptosternoid fishes (Teleostei: Siluriformes: Sisoridae). Cybium 20, 115-159.

Hora, S. L. \& Silas, E. G. (1952). Evolution and distribution of glyptosternoid fishes of the family Sisoridae (Order: Siluroidea). Proceedings of the National Institute of Science, India 18, 309-322.

Ng, H. H. \& Kottelat, M. (1999). Oreoglanis hypsiurus, a new species of glyptosternine catfish (Teleostei: Sisoridae). Ichthyological Exploration of Freshwaters 10, 375-380.

Ng, H. H. \& Rainboth, W. J. (2001). A review of the sisorid catfish genus Oreoglanis (Siluriformes: Sisoridae) with descriptions of four new species. Occasional Papers of the Museum of Zoology, The University of Michigan 732, 1-34. 